\title{
Correction to: On the effectiveness of exponential type orbitals with hyperbolic cosine functions in atomic calculations
}

\author{
E. Sahin'1 - T. Ozdogan'2 - M. Orbay ${ }^{3}$
}

Published online: 6 October 2017

(C) Springer International Publishing AG 2017

\section{Correction to: J Math Chem (2017) 55:1849-1856 DOI 10.1007/s10910-017-0764-6}

The original version of this article unfortunately contained an error. The first author's name was missing in Reference 22.

The corrected Reference is given below.

\section{Reference}

22. I.I. Guseinov, M. Erturk, Int. J. Quantum Chem. 112, 1559 (2012)

The online version of the original article can be found under doi:10.1007/s10910-017-0764-6.

$凶 \quad$ E. Sahin

ercan.sahin@amasya.edu.tr

1 Tasova Vocational School, Amasya University, Amasya, Turkey

2 Department of Computer Education and Instructional Technology, Faculty of Education, Amasya University, Amasya, Turkey

3 Department of Elementary Education, Faculty of Education, Amasya University, Amasya, Turkey 